\title{
Mitral valve repair: Is the cheese factory moving?
}

\author{
Tirone E. David, MD
}

\author{
From the Division of Cardiovascular Surgery of Peter Munk Cardiac Centre at Toronto General Hospital and \\ University of Toronto, Toronto, Ontario, Canada. \\ Disclosures: Author has nothing to disclose with regard to commercial support. \\ Received for publication March 1, 2016; accepted for publication March 1, 2016; available ahead of print March \\ $25,2016$. \\ Address for reprints: Tirone E. David, MD, 200 Elizabeth St 4N453, Toronto, ON, Canada M5G 2C4 (E-mail: \\ tirone.david@uhn.ca). \\ J Thorac Cardiovasc Surg 2016;151:1455-6 \\ $0022-5223 / \$ 36.00$ \\ Copyright (C) 2016 by The American Association for Thoracic Surgery \\ http://dx.doi.org/10.1016/j.jtcvs.2016.03.002
}

When I delivered the American Association for Thoracic Surgery Presidential Address in 2005, I mentioned that changes in surgery are inevitable, and we either adopt them and carry on or resist them and perish like the mouse and the little people in the fable Who Moved My Cheese by Dr Spencer Johnson. Surgery through small incisions and ports using long shaft instruments or robotic-assisted instrumentation is here to stay, and its role is expanding. Actually, cardiac surgery is way behind other surgical specialties when it comes to minimally invasive procedures. One of the reasons is that open-heart operations require cardiopulmonary bypass and an empty and still heart to repair congenital and acquired defects. In addition, we often work inside a complex organ instead of on its surface. For these reasons, the infrastructure required for thoracoscopic and in particular robotic-assisted heart surgery is complex and unique. This issue of the Journal contains an important document on a pathway to establish a successful roboticassisted cardiac surgery, authored by a group of experts ${ }^{1}$ who candidly describe the complexities of developing such program. As with any new initiative in cardiac units, a surgeon leader is indispensable, but the difference is that a larger number of fully dedicated personnel is required, including hospital administration for financial support (acquisition and maintenance of robotic equipment and increased operating times), anesthetists with extensive experience in cardiac anesthesia (echocardiography, single-lung ventilation, percutaneous cannulation of the superior vena cava and coronary sinus), perfusionists, dedicated surgical assistant, dedicated operating room nurses, and robot technical personnel. ${ }^{1}$ The surgeon must be trained in manipulating the robotic arms, and apparently this can be done in an experimental laboratory. ${ }^{2}$ The most common application of robotic-assisted cardiac surgery has been with mitral valve repair, and the surgeon must be experienced in repairing mitral and tricuspid valves. ${ }^{2,3}$ This is an important requirement, and because most surgeons in the United States perform less than 10 mitral valve operations per year, ${ }^{4,5}$ it is unrealistic to expect that we all can be experts in mitral valve repair and even less in

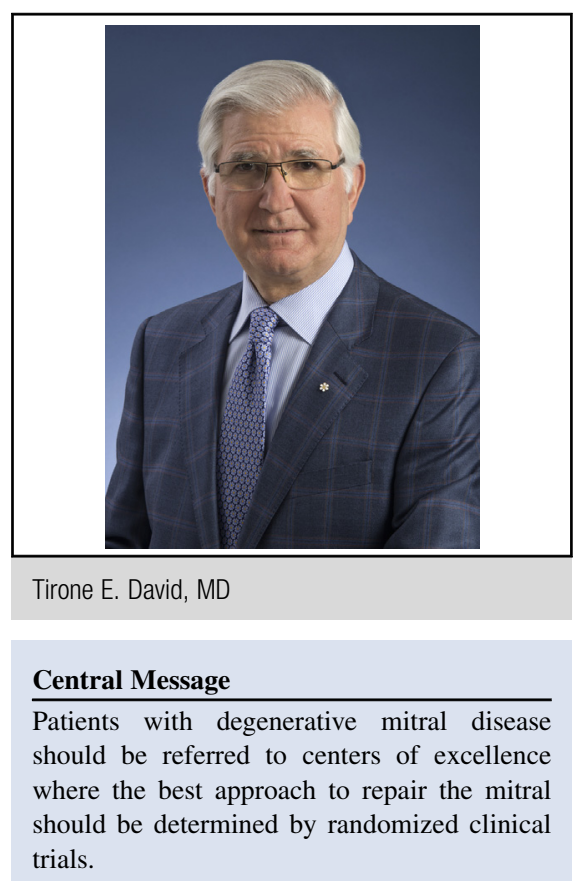

See Editorial page 1450 .

robotic mitral valve repair. Suri and colleagues ${ }^{3}$ indicate that robotic mitral valve repair is feasible in all types of degenerative mitral valve disease, including patients with advanced myxomatous degeneration of the mitral valve with prolapse of multiple segments. They also suggest that robotic mitral valve repair is associated with fewer perioperative complications, more rapid patient recovery, quicker return to normal activity, and excellent durability when compared with conventional mitral valve repair. ${ }^{3}$ As I read their editorial, I felt guilty that I have not embraced this technology and that I may not be giving my patients the best possible care.

In a recent editorial in the Journal of the American College of Cardiology, Bonow and Adams ${ }^{6}$ suggest that the "time has come to define centers of excellence in mitral valve repair" to increase the repair rate in patients with degenerative disorders of the mitral valve and to improve the outcomes of this operation, particularly its durability. Centralization of specialized health care services is difficult even in countries with socialized medicine, such as England and Canada, because all surgeons believe they are qualified to manage patients with mitral regurgitation. ${ }^{4,6,7}$ I believe that mitral valve repair is not an operation for all cardiac surgeons because a large number of cases per year are needed to acquire and maintain the skills necessary to 
consistently provide good results. ${ }^{7}$ I also believe that surgeons such as Suri and colleagues ${ }^{3}$ and others who claim that mitral valve repair is better with robotic technology than under direct vision through the sternum should initiate a multicenter prospective randomized clinical trial comparing these 2 approaches. Unless experts like them can prove to us that what they are doing is better than what most of us do, the cheese is not going to move.

\section{References}

1. Rodriguez E, Nifong W, Task Force Committee Members. Pathway for surgeons and programs to establish and maintain a successful robot-assisted adult cardiac surgery program. J Thorac Cardiovasc Surg. 2016 [In review].
2. Valdis M, Chu MWA, Schlachta C, Kiaii B. Evaluation of robotic cardiac surgery simulation training: a randomized controlled trial. J Thorac Cardiovasc Surg. 2016;151:1498-505.e2.

3. Suri RM, Dearani JA, Mihalievic T, Chitwood W Jr, Murphy DA, Trento A, et al. Mitral valve repair using robotic technology: safe, effective and durable. J Thorac Cardiovasc Surg. 2016;151:1450-4.

4. Bolling SF, Li S, O'Brien SM, Brennan JM, Prager RL, Gammie JS. Predictors of mitral valve repair: clinical and surgeon factors. Ann Thorac Surg. 2010;90: 1904-11.

5. LaPar DJ, Ailawadi G, Isbell JM, Crosby IK, Kern JA, Rich JB, et al. Mitral valve repair rates correlate with surgeon and institutional experience. J Thorac Cardiovasc Surg. 2014;148:995-1004.

6. Bonow RO, Adams DH. The time has come to define centers of excellence in mitral valve repair. J Am Coll Cardiol. 2016;67:499-501.

7. Bridgewater B, Hooper T, Munsch C, Hunter S, von Oppell U, Livesey S, et al. Mitral repair best practice: proposed standards. Heart. 2006;92:939-44. 